\title{
A NEW SPECIES OF TRACHYSPHYRUS FROM THE ANDES OF ECUADOR (HYMENOPTERA, ICHNEUMONIDAE)
}

\author{
By Charles C. Porter \\ Biological Laboratories, Harvard University
}

The author has just completed a revision of the South American species of the otherwise primarily Holarctic ichneumonid genus Trachysphyrus Haliday. This monograph is scheduled to be published before the end of 1967 by the American Entomological Institute. Although nearly Ioo species are there treated, collections from much of South America are so inadequate that the discovery of many additional forms is to be anticipated. Indeed, several more species have come to the author's attention after the acceptance of his manuscript for publication. Some of these are represented by single specimens and their description seems best postponed until larger series are obtained. The species treated here, however, is available in sufficient numbers to make possible a complete and reliable diagnosis and is also interesting as the second member of its genus to be described from the very poorly known Ecuadorian fauna.

\section{Trachysphyrus hoplites n. sp. Figures I, 2. Map I.}

Types: Holotype: (female) ecuador (Cerro Tinajillas, $3200 \mathrm{~m}$., March I8-2i, i965, L.E. Peña) (Townes). Paratypes: ( I female and 6 males). ECUAdor (Cerro Tinajillas, $3200 \mathrm{~m}$., March I8-2 I, I965, L.E. Peña; Targui, ${ }^{1}$ 2800 m., March 7-8, I965, L.E. Peña) (Cambridge, Porter, Townes).

Female: Color: antenna blackish with a white band, or sometimes only dull brownish staining, above on flagellomeres 5-9; head, thorax, and propodeum black with white markings as follows: dull patch just above mandibular condyle; sometimes tiny spot in middle of face below antennal sockets; orbital line: more or less interrupted on bottom of eye, on about lower $1 / 4$ of hind-orbit, and sometimes irregularly near top of eye; transverse blotch on collar; narrow line, fragmented to practically complete, on latero-dorsal margin of pro-

\footnotetext{
${ }^{1}$ There is no such locality in atlases and gazetteers available to me. Probably this is a misspelling of Tarqui, a village in the same part of Ecuador as Cerro de Tinajillas.

Manuscript received by the editor March 15, 1967.
} 
notum; spot or blotch on subalarum; and pair of small spots on base of scutellum; gaster pale orange; legs black, slightly brownish-stained especially on tarsi; wings vaguely darkened, particularly toward apex. Length of fore-wing: $7.0-7.4 \mathrm{~mm}$. Flagellum: rather stout, slightly flattened below toward apex, Ist segment 5.0-5.7 times as long as deep apically. Clypeus: high, more or less symmetrically convex to bluntly subpyramidal in profile; apical margin almost truncate to gently convex, unusually sharp and a little reflexed especially toward corners. Malar space: I.2-I.3 times as long as basal width of mandible. Temple: 0.4-0.5 times as long as eye in dorsal view; strongly, directly receding. Genal and Oral Carinae: genal carina sharp and narrow, joining the moderately elevated oral carina below. Foretibia: not inflated. Pronotum: submarginal groove distinct but rather narrow and shallow; epomia strong in scrobe, continued, usually more irregularly, a subequal or greater distance below, often
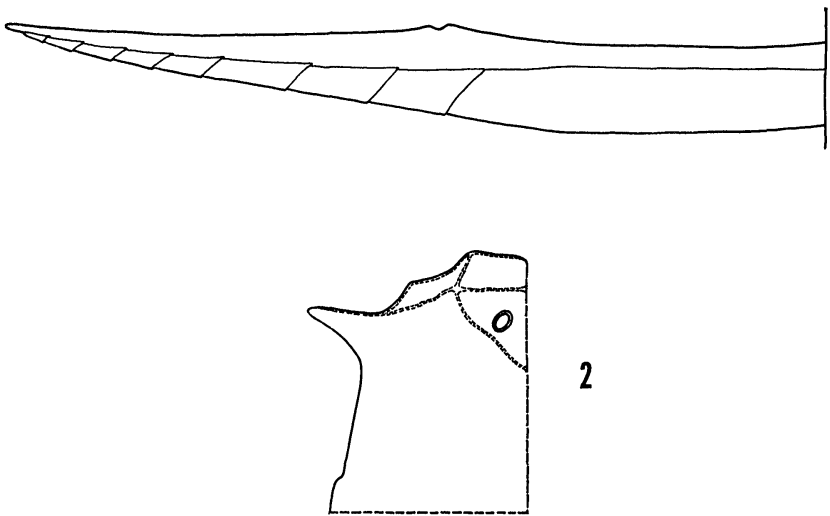

Fig. 1. Trachysphyrus hoplites $\mathrm{n}$. sp. female. Lateral view of apex of ovipositor.

Fig. 2. Trachysphyrus hoplites n. sp. female. Lateral view of propodeum.

gently traceable mesad above but without a definite swelling above its upper end. Mesoscutum: notauli narrow and shallow, traceable about $1 / 2$ the length of mesoscutum; surface largely mat, granularly puncto-reticulate: dullest with more distinct small, shallow punctures and intercalated micro-reticulation toward centers of lobes; more nearly shining and with stronger wrinkling along notauli, over a broad area behind their terminus, and on peripheries of lateral lobes. Mesopleuron: subalarum an unusually thin, crescentic lamella; speculum swollen and shining but often much invaded by strong 
punctures and wrinkles; surface otherwise with rather coarse reticulate wrinkling. Wing-Venation: radial cell 3.8-4. I times as long as wide; areolet large, intercubiti strongly convergent above, 2nd abscissa of radius 0.7-0.8 times as long as Ist intercubitus; 2nd recurrent slightly inclivous or nearly vertical, gently and almost evenly outcurved or more strongly curved on upper $1 / 2$; disco-cubitus broadly angled, without or with a short to moderately long ramellus; nervulus a little antefurcal to interstitial; mediella gently arched throughout; upper part of nervellus I.6-I.7 times as long as lower; axillus close to hind-margin of wing. Propodeum: short and high, faces subequal: basal moderately sloping behind, apical almost vertically declivous; spiracle I.2-I.3 times as long as wide; basal trans-carina sharp throughout, in places a little irregular, strongest and forming low-crescentic or subcuneate cristae laterad; apical trans-carina detectable but very irregular, especially medially; cristae of apical trans-carina exceptionally large and strongly projecting ligulate; median longitudinal carinae vague or weak and irregular, areola definitely wider than long in position; lateral longitudinal carinae irregularly traceable basad, becoming stronger between trans-carinae and, especially, as they continue onto cristae behind; surface strongly reticulately wrinkled, a little more weakly sculptured basad of basal trans-carina. Ist gastric segment: no expansion at base of petiole; postpetiole moderately broadened, I.I-I.3 times as wide apically as long from spiracle to apex; ventro-lateral carina traceable throughout, strongest on postpetiole; dorso-lateral carina traceable throughout, sharp on postpetiole; dorsal carinae finely detectable on most of petiole and base of postpetiole, strongest apicad; surface of postpetiole smooth and shining with fine, rather weak micro-reticulation which fades out near apex and small, obscure, scattered punctures that emit moderately short, mostly well-separated setae. 2nd gastric tergite: a little dully shining, with distinct fine and weakly granular micro-reticulation and numerous small, very obscure punctures that emit short, largely widely-separated setae which may become somewhat longer and denser, but not extensively overlapping, laterad and apicad. Gaster: rather elongate fusiform ; setae of following tergites may be generally somewhat denser than those on 2nd. Ovipositor: sheathed portion 0.3 times as long as fore-wing; straight, moderately slender, compressed; nodus low, with a rather large, shallow notch; dorsal valve with a long, nearly direct to slightly concave taper between notch and apex; ventral valve with fine, well-spaced oblique ridges on tip; tip 0.I6-0.I9 times as high at notch as long from notch to apex.

MALE: differs from female as follows: Color: no pale band on 
flagellum; clypeus more or less broadly white; white on orbits broadly interrupted at top of eye and often not or only slightly interrupted at bottom: band on front-orbit usually broader, particularly on face; that on hind-orbit narrow but with a broader extension across malar space below, or sometimes interrupted on lower $\mathrm{I} / 4$ but with a detached mark in malar space; sometimes no white on collar; apex of propleuron sometimes more or less white; white spot on base of tegula; sometimes no white on subalarum; sometimes no white on scutellum or sometimes white spots at base of scutellum even larger than in female; Ist gastric segment mostly black, or becoming more or less pale orange on postpetiole; tergites $2-4$ or 5 or 6 pale orange; succeeding tergites blackish, often grading into pale orange laterad and often with dull, narrow whitish apical bands; fore-coxa dully and irregularly to very broadly and brightly white externo-ventrally; fore-trochanter sometimes largely white below; mid-coxa sometimes with a ventral or externo-ventral white spot; mid-trochanter sometimes partly white below; often more or less of hind-tarsomeres 2 (apically) or 3-4 white or hind-tarsus sometimes with only a trace of pale staining. Length of fore-wing: $5.7-7.2 \mathrm{~mm}$. Ist flagellomere: 3.5-4.2 times as long as deep apically. Malar Space: 0.9-I.O times as long as basal width of mandible. Temple: 0.8-0.9 times as

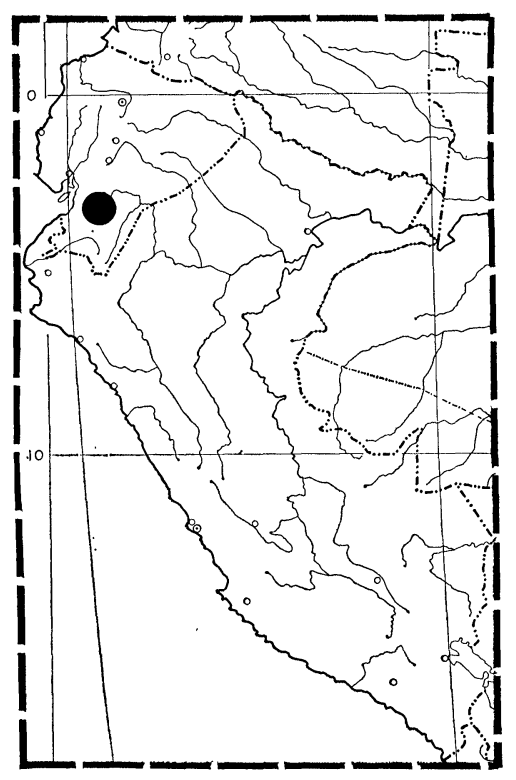

Map 1. Distribution of Trachysphyrus hoplites n. sp. (Ecuador). 
long as eye in dorsal view, a little less strongly receding and often slightly rounded-off. Mesoscutum: notauli traceable about I/2-2/3 the length of mesoscutum. Wing-Venation: 2nd abscissa of radius O.6-I.O times as long as Ist intercubitus; upper part of nervellus I.22.3 times as long as lower. Propodeum: a little longer and lower than in female with basal face more strongly sloping behind; spiracle I.4-1.6 times as long as wide; basal trans-carina often very sharp and high; apical trans-carina often stronger than in female, but irregular; areola much wider than long in position; lateral longitudinal carinae averaging stronger and less irregular than in female, sharp basally and very high passing onto crista behind. Ist gastric segment: postpetiole weakly expanded or almost parallel-sided, 0.7-0.8 times as wide apically as long from spiracle to apex; dorso-lateral carina fine but sharp, except sometimes weaker toward base on petiole; dorsalcarinae largely weakly suggested or quite sharp, at least toward apex of petiole and on base of postpetiole; micro-reticulation of postpetiole weaker, fading out well before apex; punctures on postpetiole averaging larger and more numerous than in female, emitting long and often in large part, but not consistently, overlapping setae. 2nd gastric tergite: punctures obscure, but larger, more numerous, and often more definitely visible than in female, emitting long setae which mostly approach to exceed the length of their interspaces; setae of following tergites a little denser than those on 2 nd.

Collections: The holotype and five paratypes are in the collection of Henry K. Townes at Ann Arbor, Michigan; a sixth paratype is in the Museum of Comparative Zoology at Harvard University and a seventh in the collection of Charles C. Porter at Metuchen, New Jersey.

Discussion: Hoplites differs from all known South American species of Trachysphyrus by the following combination of characters: gaster orange in female, black with extensive orange on intermediate tergites in male; clypeal margin unusually sharp and slightly reflexed; subalarum a thin, crescentic lamella; no contrastingly smoother area on mesopleuron along prepectal carina opposite speculum; mediella gently arched; axillus close to hind-margin of wing; propodeal cristae very large and prominently projecting; propodeal spiracle short-oval to almost round; setae of female 2nd gastric tergite for the most part widely separated; ovipositor only 0.3 times as long as fore-wing, its tip only o.I6-O.I9 times as high at notch as long from notch to apex.

Within Trachysphyrus, the present species is an aberrant member of the cosmopolitan but predominantly Holarctic and temperate South 
American Albitarsis Group, as defined by Townes (1962, p. 219). Its discovery extends considerably northward the known distribution of the Albitarsis Group in Andean South America, for previously no species of this assemblage had been recorded beyond Cuzco in central Perú. There still remains a gap in our knowledge of the Albitarsis Group between Ecuador and San José de Costa Rica (Volcán Irazú) in Central America, but the finding of an Ecuadorian species supports the impression that this lacuna is not a natural fact but merely the result of insufficient collecting in the northern Andes.

Among its relatives, Hoplites is closest to a species from the mountains of Tucumán Province of northern Argentina ${ }^{2}$ with which it shares many features of color, sculpture, wing-venation and proportion but from which it differs principally in its partially orange instead of wholly black male gaster, longer malar space ( I.2-I.3 times as long as basal width of mandible in female and 0.9-I.o times in male versus I.O times in female and 0.8-0.9 times in male), very thin instead of rather thick and swollen subalarum, much larger and longer propodeal cristae, and in having a large notch on the ovipositor tip while the Argentine species is almost unique in lacking a notch. The differences noted are of a type which experience has shown to have specific value among the South American Trachysphyrus. Nonetheless, we know nothing of what happens to these forms in the mediate Andes of Perú and Bolivia, so that future collecting in those regions might turn up intergrading populations. It seems much more probable, however, that in this case we are dealing with two distinct members of a subgroup which will eventually prove to have several other species in Andean South America.

In addition to T. hoplites, only Trachysphyrus metallicus (Cameron) is known from the Andes of Ecuador. Metallicus is a large, brilliantly blue-green species in which the axillus vein of the hindwing is intermediate between the posterior margin of the wing and the submediella and in which the nodus of the ovipositor tip bears a huge notch that gives rise to a prominent, forward-directed groove. Metallicus belongs to the strictly South American Imperialis Group and is also the northernmost representative of its series.

Further collecting will probably show that other groups of Trachysphyrus are present in Ecuador. The very broad and complex Andean mass which stretches from Ecuador through Perú and Bolivia to

\footnotetext{
${ }^{2}$ This species is No. 23 in the author's monograph of the South American Trachysphyrus. It is not given a name here because there is uncertainty as to whether this shorter paper or the larger work will be published first and it is desired to validate the name of the Argentine species in the latter.
} 
northern Argentina appears to be a major center of diversification for Trachysphyrus in South America (on the basis of the fairly well collected Peruvian fauna). Indeed, it is likely the first and most important of such centers of diversification as Trachysphyrus gives evidence of being an autochthonously Holarctic genus which entered South America from the north along the high temperate corridor afforded by those mountains that buttress the whole western edge of the New World.

Specific Name: Hoplites is a Greek noun meaning "heavy-armed foot-soldier". It was chosen in reference to the tremendous propodeal apophyses that characterize this species.

Acknowledgements: This paper was conceived during a visit to the American Entomological Institute (Ann Arbor, Michigan) made possible by funds from the Evolutionary Biology Committee of the Harvard Biology Department. Dr. H. K. Townes of the American Entomological Institute arranged for the loan of the series described and kindly allowed the retention of paratypes for the Museum of Comparative Zoology and for the author's personal collection.

Porter, C. C.

\section{REFERENCES}

1967. A Systematic Revision of the South American Species of the Genus Trachysphyrus Haliday (Hymenoptera, Ichneumonidae). In press. Accepted for publication in 1967 as a Memoir of the American Entomological Institute.

Townes, H. K. AND M. Townes

1962. Ichneumon Flies of America North of México: Gelinae: Mesostenini. Bull. U.S. Nat. Mus. 216 (pt. 3). 

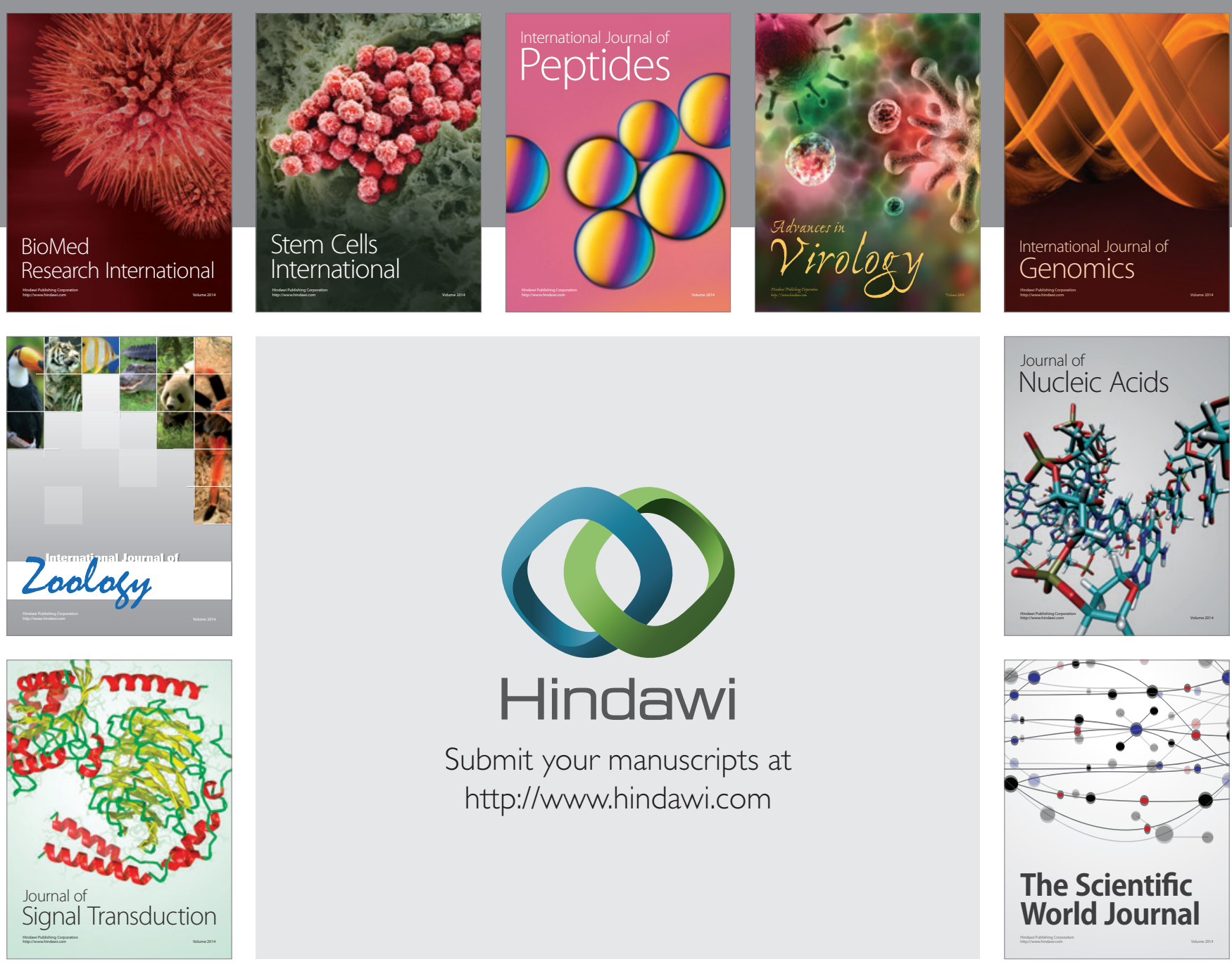

Submit your manuscripts at

http://www.hindawi.com
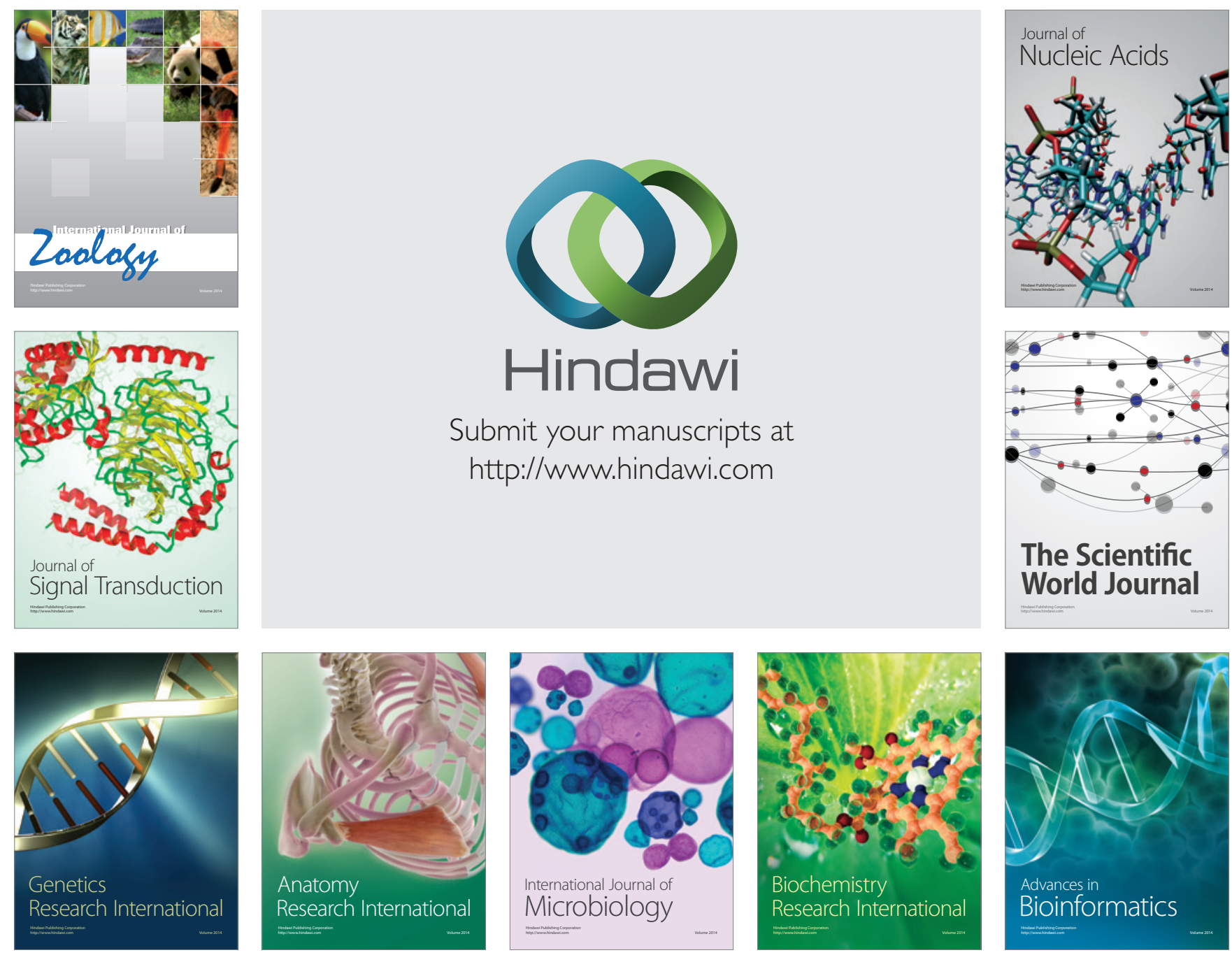

The Scientific World Journal
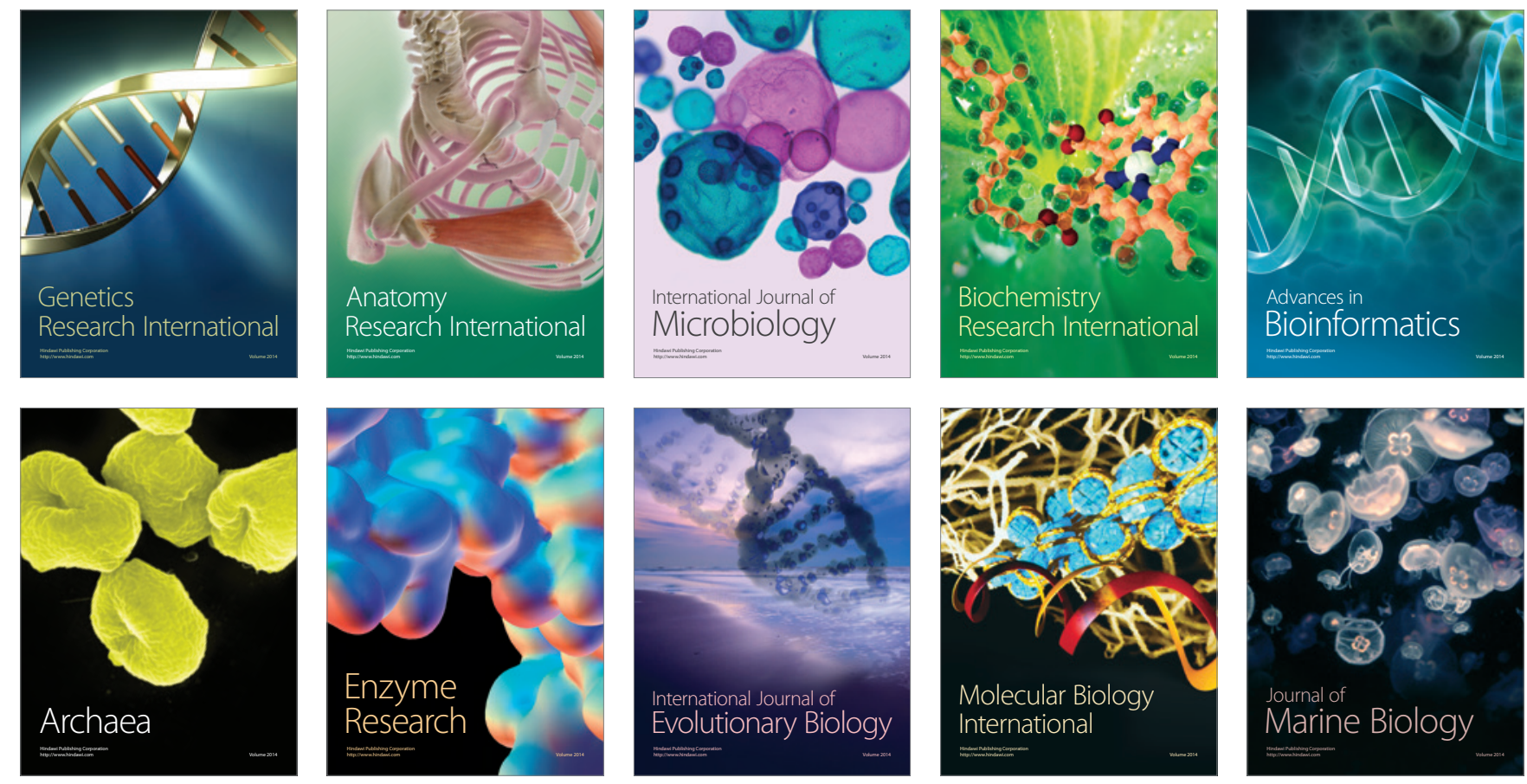